\title{
A new Thelastomatidae, Oryctophila bonaerensis sp. nov. (Nematoda) parasite of curculionid beetle larvae of Prosalbus rufus (Coleoptera: Curculionidae) from Argentina
}

\author{
Nora B. Camino \& María Fernanda Achinelly
}

Investigador CIC, Centro de Estudios Parasitológicos y de Vectores, CEPAVE. Calle 2, n 584, 1900 La Plata, Argentina. E-mail: nemainst@cepave.edu.ar

\begin{abstract}
Oryctophila bonaerensis sp. nov. parasitizing curculionid beetle larvae from Argentina, is described and illustrated. The species is characterized by a prominent genital cone and a short and filiform tail appendage. Female with vulva at midlenght of body, vagina long, S-shaped, monodelphic, opistodelphic. Male with one club-shaped spicule. Genital papillae arranged as follows: one pair of large preanal papillae and three pairs of postanal papillae of various sizes: a pair of medium sized papillae is immediately posterior to the anus, followed by a pair of large papillae, and one pair of small papillae at the base of the caudal appendage.
\end{abstract}

KEY WORDS. Nematodes; Entomoparasitic; Insect; taxonomy.

All species currently included in Johnstonia Basir, 1956, had been at some point included in either Oxyuris Rudolphi, 1803, or in Thelastoma Leidy, 1849, based on the overall shape of the esophageal bulb. Johnstonia has been separated from the latter on the basis of the number of uterine branches: Thelastoma is didelphic and Johnstonia is monodelphic (BASIR 1956). Thus, BASIR (1956) proposed Johnstonia to group Pinworms (Nematoda: Oxyurida), parasites of beetle (Coleoptera) in Australia. Because the type species was insufficiently described, JARRY \& JARRY (1968) suggested that the entire genus was based on a misinterpretation of the morphology of the female reproductive system. However, JoHnson's (1914) illustration of the female clearly shows a monodelphic worm which bears close resemblance to vaN WAEREBEKE's (1973) Oryctophyla; both are from scarabaeid larvae and have the anterior lip of the vulva protruding. ADAMSON \& vaN WAEREBEKE (1992) reviewed Thelastomatoidea. They recognized Johnstonia as a valid genus based on the fact the female is monodelphic. Adamson \& van WaerebeKe (1994) considered Oryctophila van Waerebeke, 1973 to be a synonym of Johnstonia Basir, 1956 because both are parasites of scarabaeid larvae and both have the anterior lip of the vulva protruding. These authors also detected that Basir's genus is homonymous with Johnstonia Quatrefages, 1866 (Polychaeta), a "nomen dubium" which the International Commission of Zoological Nomenclature decided to retain with the suppression of Johnstonia Basir, 1956. ADAmson \& VAN W AEREBEKE (1994) suggested that Oryctophila van Waerebeke, 1973 is used to accommodate species with monodelphic females formerly assigned to Basir's genus. We report a new species of the genus, Oryctophila bonaerensis sp. nov., a parasite of curculionid beetle larvae from Buenos Aires, Argentina.

\section{MATERIAL AND METHODS}

Larvae of Prosalbus rufus Oglobbin, 1930 (n = 12) from Gorina ( $\left.34^{\circ} 58^{\prime} \mathrm{S}, 57^{\circ} 54^{\prime} \mathrm{W}\right)$, La Plata, Buenos Aires Province, Argentina, were collected by hand and placed in individual vials. We followed POINAR's (1975) dissection protocol, keeping insects at $5^{\circ} \mathrm{C}$ for 10 minutes, and then dissecting them in Petri dishes filled with distilled water under a Zeiss stereoscope. The nematodes were euthanized in $60^{\circ} \mathrm{C}$ distilled water for two minutes. They were subsequently removed to $50 \%$ TAF solution in water for 48 hours, and then transferred into pure TAF. The nematodes were transferred from the fixative to glycerol for clearing. Fixed specimens were used for drawings using a camera lucida mounted on a Zeiss compound microscope. All measurements are in $\mu \mathrm{m}$ (holotype male and allotype female), with ranges in parenthesis (paratypes).

\section{TAXONOMY}

\section{Oryctophila bonaerensis sp. nov.}

Figs 1-6

Description: small nematodes; cuticle annulated throughout length of body. Female: cephalic extremity (Fig. 1) formed by circumoral annule (diameter $40 \mu \mathrm{m}$ ) and enlarged second annule (diameter $52 \mu \mathrm{m}$ ). Buccal cavity short, cylindrical with simple walls. Esophagus with a corpus, an isthmus and a basal bulb. Nerve ring located in the middle of the corpus. Excretory pore situated at mid-isthmus level. Female with vulva at midbody, with posterior lip well developed (Fig. 3). Vagina long, S-shaped. Monodelphic, opistodelphic. Eggs broadly oval. Tail 

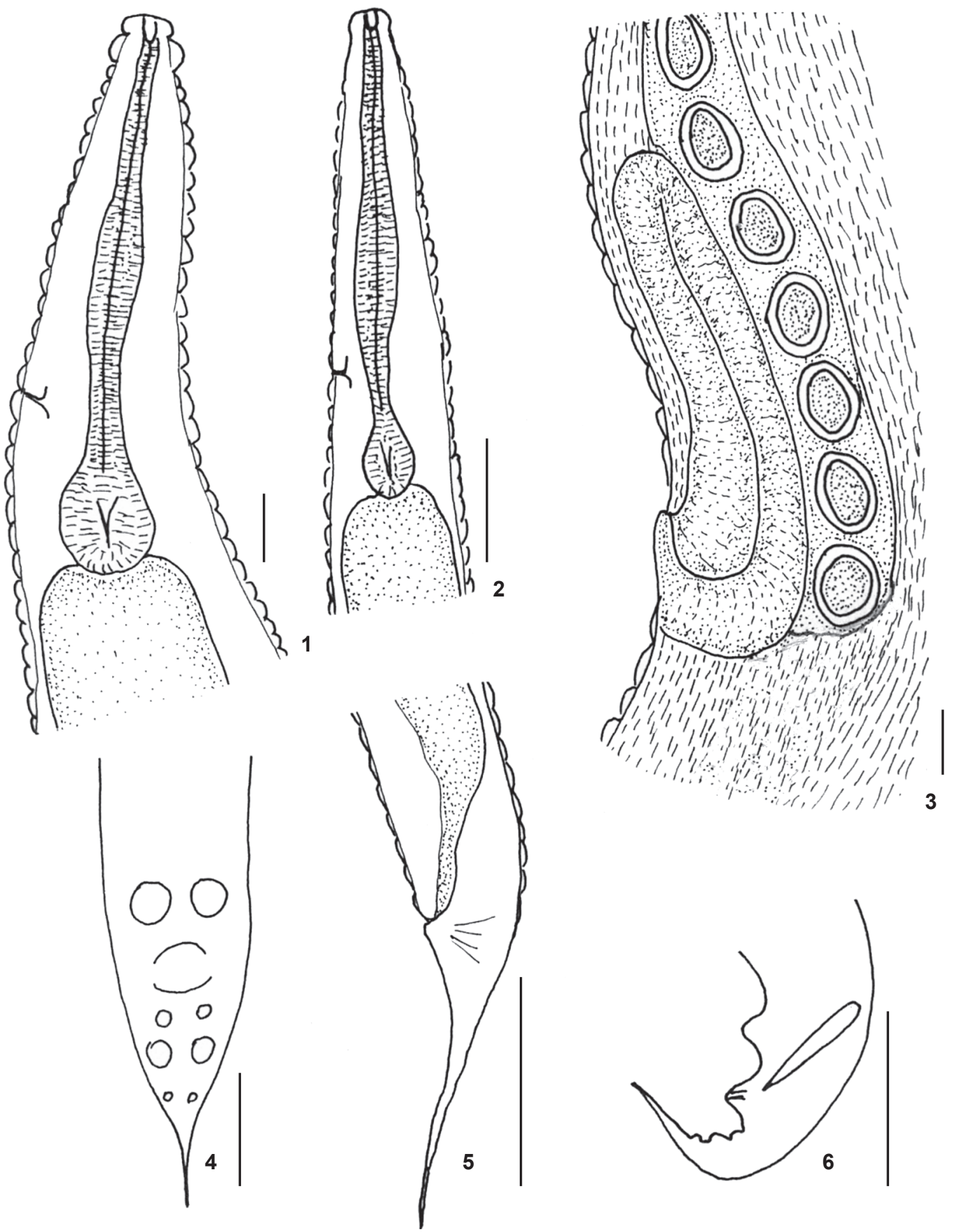

Figures 1-6. Oryctophila bonaerensis sp. nov.: (1) anterior end of the female; (2) anterior end of the male; (3) vagina, uterus with eggs; (4) posterior end of the male, ventral view; (5) posterior end of the male; (6) lateral view posterior end of the female; Scale bars $=50 \mu \mathrm{m}$.

long and filiform (Fig. 5). Male: cephalic extremity (Fig. 2) formed by simple annule (diameter $17 \mu \mathrm{m})$. Stoma simple with thin walls. Nerve ring at midlevel of corpus. Excretory pore at mid-isthmus level. Genital cone prominent, with a short and filiform tail appendage (Fig. 6). The male with testis extending to middle of the body. One club-shaped spicule, without gubernaculum. The genital papillae arranged with one large pair preanal papillae and three pairs postanal, of these, one pair 
medium size just behind the anus, medial pair large and distal pair small at base of the caudal appendage (Fig. 4).

Male ( $\mathrm{n}=9$ ) body length: $1200 \mu \mathrm{m}(1050-1360)$; head width at mouth level: $16.2 \mu \mathrm{m}$ (14.4-18); oesophagus length: $220 \mu \mathrm{m}$ (188-292.4); distance from anterior end to excretory pore: $160 \mu \mathrm{m}$ (142.8-182); greatest body diameter: $72.6 \mu \mathrm{m}$ (71.2-76.2); spicules length: $38 \mu \mathrm{m}$ (36.8-42.2); gubernaculum length: $20 \mu \mathrm{m}$ (18.6-22); tail appendage length: $20 \mu \mathrm{m}$ (1925.4).

Female ( $\mathrm{n}=14)$ body length: $5300 \mu \mathrm{m}$ (4630-5800); head width at mouth level: $40 \mu \mathrm{m}$ (40-43.6); oesophagus length: 670 $\mu \mathrm{m}$ (660-696.5); distance from anterior end to excretory pore: $470 \mu \mathrm{m}$ (402-520); width of body at level of vulva: $450 \mu \mathrm{m}$ (420-455); greatest body diameter: $420 \mu \mathrm{m}$ (396-445); vagina length: $260.5 \mu \mathrm{m}$ (242-286.6); distance anterior end to vulva/ total length $x 100(\mathrm{~V}): 59.43 \%$ (58.6-61.2); length and width of eggs: $68 \mu \mathrm{m}(64-70.8)$ x $44 \mu \mathrm{m}$ (41-46.2); tail appendage length: $55.7 \mu \mathrm{m}(52.6-58.2)$.

Type host: larvae of Prosalbus rufus Oglobbin (Coleoptera: Curculionidae).

Type locality: Gorina ( $\left.34^{\circ} 58^{\prime} \mathrm{S}, 57^{\circ} 54^{\prime} \mathrm{W}\right)$, La Plata, Buenos Aires, Argentina.

Site in host: intestine, midgut.

Etymology: the name refers to the geographical region where it is found.

Type material: holotype male and allotype female are deposited in the Helminthological collection of Museo de Ciencias Naturales de La Plata, $n^{\circ} 5483$, paratypes in the Nematological collection of CEPAVE (Dr. Camino's laboratory).

\section{DISCUSSION}

Females of Oryctophila bonaerensis sp. nov. are similar to four other species of Oryctophila: O. alatum (Johnaston, 1914) Basir, 1956, parasite of a cetonid beetle larva from Australia; $O$. crimense (Skrjabin, 1927) Basir, 1956, from myriapods from Russia; O. myriapodicola (Skrjabin, 1916) Basir, 1956, from myriapods from Africa, and O. sphaeropoli (Parona, 1896) Basir, 1956, from millipedes from Indonesia. The female reproductive apparatus of these species is similar, including a monodelphic, opistodelphic condition. Two traits distinguish O. alatum from
O. bonaerensis: First, the latter has a pair of caudal papillae near the anus; second, the intestine of $\mathrm{O}$. bonaerensis is dilated anteriorly to form a cardia. The males have not been described for the other three species; therefore, the comparisons below are based on females. O. crimense has larger eggs (113 x $85 \mu \mathrm{m} v s$ in O. bonaerensis (64-70.8 x 41-46.2 $\mu \mathrm{m})$ and a more anterior excretory pore (in the middle of the corpus). Oryctophila myriapodicola differs by having a shorter tail (about one-fifth of the body, 460-510 $\mu \mathrm{m}$ ), and the intestine enlarged anteriorly forming a distinct cardia, which occupies almost the entire width of body. Finally, J. sphaeropoli is characterized by having a distinct sub-spherical swelling of the posterior end of the corpus in the shape of a pseudobulb and a spicate, filiform tail of about one-third the length of the body (980-1430 $\mu \mathrm{m})$.

\section{LITERATURE CITED}

Adamson, M.L. \& D. van Waerebeke. 1992. Revision of the Thelastomatoidea, Oxyurida of invertebrate hosts I. Thelastomatidae. Systematic Parasitology 21: 21-63.

Adamson, M.L. \& D. van Waerebeke. 1994. Oryctophila van Waerebeke, 1973 (Oxyurida: Nematoda) proponed for Johnstonia Basir, 1956, junior homonym of Johnstonia Quatrefages, 1866 (Polychaeta: Annelida). Systematic Parasitology 29: 79.

BASIR, M.A. 1956. Oxyuroid parasites of arthropods. A monographic Study. I Thelastomidae. 2. Oxyuridae. Zoologica 38 (2): 1-79.

JARRY, D.M. \& D.T. JARRY. 1968. Tentative de clarification a propos de 60 especes des genres Cephalobellus et Thelastoma (Nematoda: Oxyuroidea). Annales de Parasitologie Humaine et Comparée 53: 339-352.

Johnson, T.H. 1914. Some new Queensland endoparasites. Proccedings of the Royal Society of Queensland 26: 7684.

Poinar JR, G.O. 1975. Entomogenous nematodes. A manual and host list of insect-nematode associations. Leiden, E.J. Brill 317p.

VAN WAEREBEKE, D. 1973. Quatres nouvelles spèces d'Oxyuroides associes aux Oryctes a Madagascar. Bulletin du Museum National d'Histoire Naturelle, Zoologie, 95 (123): 535-553.

Submitted: 15.IV.2010; Accepted: 27.II.2011. Editorial responsibility: Marcus V. Domingues 